\title{
Case Report: Struma Ovarii of Right Ovary
}

\author{
Akula Srujana1, K. Venkat Ram Reddy ${ }^{2}$ \\ ${ }^{1}$ Post Graduate, Department of Radio-diagnosis, 2Professor and HOD, Department of Radio-diagnosis, SVS Medical College, \\ Mahabubnagar, Telangana, India
}

Corresponding author: Akula Srujana, Post Graduate, Department of Radio-diagnosis, SVS Medical College, Mahabubnagar, Telangana, India

DOI: http://dx.doi.org/10.21276/ijcmsr.2020.5.2.1

How to cite this article: Akula Srujana, K. Venkat Ram Reddy. Case report: struma ovarii of right ovary. International Journal of Contemporary Medicine Surgery and Radiology. 2020;5(2):B1-B3.

\section{A B S T R A C T}

Introduction: Struma ovarii is a very rare and usually benign ovarian tumour. Struma ovarii is the monodermal teratoma and is characterised by presence of macroscopically and histologically detectable thyroid tissue containing variable sized follicles with colloid material (2). Radiologically it is difficult to differentiate between benign or malignant ovarian tumour. In this case report we present a case of benign struma ovarii in right ovary with elevated CA- 125 levels.

Case report: We present a case of 45 years old female patient who presented with abdominal distension and elevated CA125 levels with multiloculated mass in right adnexa with solid and cystic components which was suspected to be ovarian malignancy. After resection and pathological examination, it turned out to be a teratoma with thyroid tissue within - struma ovarii.

Conclusion: The sonographic and MRI features of struma ovary may mimic ovarian malignancy when presented with complex ovarian mass with ascites and elevated CA125 levels. The final diagnosis of struma ovarii is based on pathology examination of resection of cyst /ovary to confirm or exclude malignancy

Keywords: Struma Ovarii, Teratoma, Ultrasound, MRI

\section{INTRODUCTION}

Struma ovarii is a rare benign ovarian tumour first described in 1889 by BOETTLIN, who observed presence of thyroid follicular tissue in ovary. Struma ovarii is a form of monodermal teratoma and is characterised by presence of macroscopically and histologically detectable thyroid tissue containing variable sized follicles with colloid material. ${ }^{2}$ Struma ovarii presents as multicystic mass with peak incidence at 5 th decade of life. according to $\mathrm{YOO}$ et al states the most common initial symptoms at presentation are abdominal pain and distension or a palpable mass. according to several authors a variable occurrence of ascites in patients with struma ovarii, ranging from $17 \%$ to $33 \%$ has been observed and it is thought that struma ovarii should be included in differential diagnosis of pelvic mass that presents with ascites, pleural effusion and elevated CA-125 tumour marker.

\section{CASE REPORT}

A 45 year old female patient P4L3D1 came with complaints of abdominal distention since 20 days. Her menstrual cycles were regular. Clinical and routine laboratory examinations were normal. Elevated CA-125 levels (886mlU/L) was noted.

Ultrasound showed multilocular cystic and solid components mass in right ovary with septa and moderate ascites (Figure -1). MRI Well-defined multiloculated T2 hyper intense cystic lesions with heterogeneously hypo intense solid components noted in right ovary with moderate ascites with

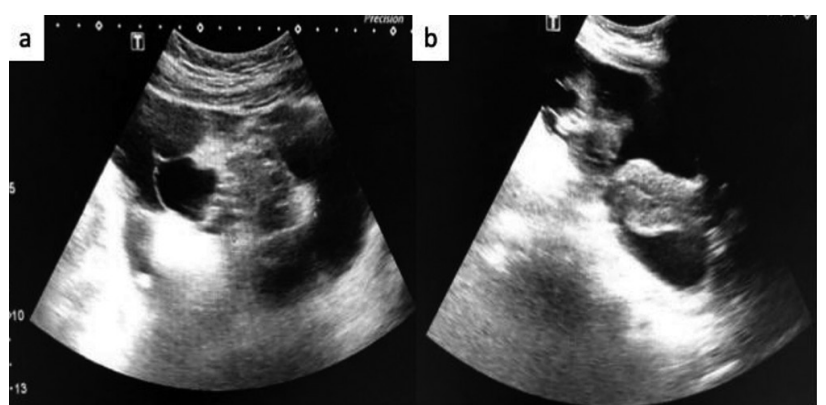

Figure-1: a) and b) A single well defined multiloculated cystic and solid components mass lesion noted in right ovary with septa $(4 \mathrm{~mm})$ with moderate ascites

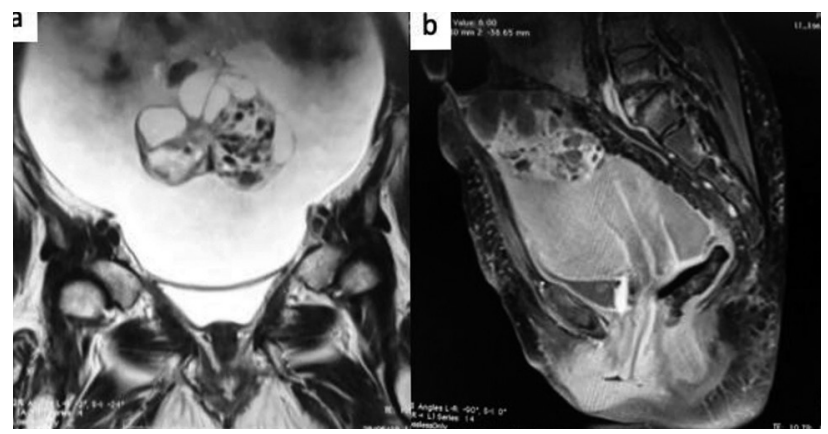

Figure-2: a) Well-defined multiloculated T2 hyper intense cystic lesions with heterogeneously hypo intense solid components noted in right ovary with moderate ascites. b) On T1 post contrast moderately enhancing solid component and septae noted 

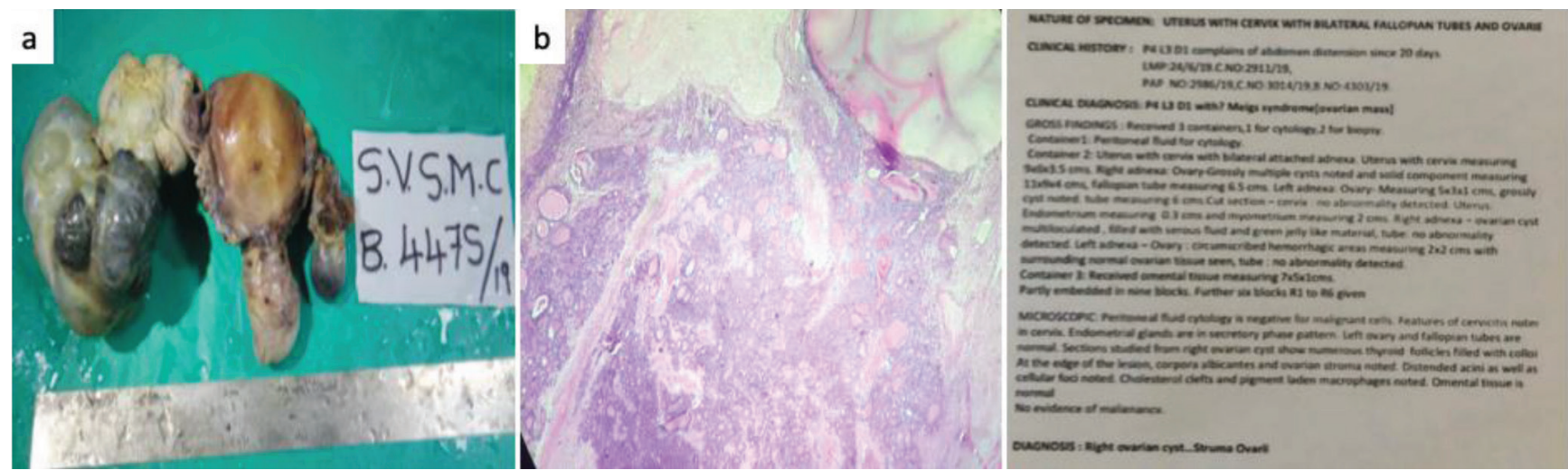

Figure-3: a) Specimen after total abdominal hysterectomy showing multiple cysts and solid component mass in right ovary. b) Microscopic features shows numerous thyroid follicles filled with colloid. c) HistoPathology Report

the septa enhancing post-contrast (Figure-2)

Provisional Diagnosis: Right malignant ovarian mass with moderate ascites

\section{Differential Diagnosis}

1. Mature cystic teratoma- Fat containing mass with peripheral blood flow and avascular central mass (floating Rokitansky nodule on fat-fluid interface

2. Mucinous cystadenoma- multicystic ovarian mass with thin septations forming multiple locules. Locules have different signal intensities on MR reflecting various concentration of mucin.

3. Thyroid cancer metastasis to the ovary

Patient underwent total abdominal hysterectomy and oophorectomy. The gross appearance of right ovarian mass with multiple cysts and solid components was seen which on microscopy revealed numerous thyroid follicles filled with colloid.(Figure-3)

\section{DISCUSSION}

Struma ovarii usually presents after age of 40 years and the peak age of incidence is in the fifth decade. ${ }^{1}$ This tumor is present in only $17.6 \%$ of cases in patients under 30 years. $^{2}$ Struma ovarii constitutes approximately $3 \%$ of all ovarian teratomas, $2 \%$ of all germ cell tumors of the ovary, and $0.5 \%$ of all ovarian tumors. ${ }^{3,4}$ Malignant transformation is uncommon, only about $5 \%$ of struma ovarii being malignant. Metastases are found in $5-6 \%$ of patients with malignant struma ovarii. ${ }^{6}$ Most cases of struma ovarii are asymptomatic ${ }^{3,5}$, but some patients complain of abdominal distension, pain, urinary or intestinal obstruction, infertility or hot flushes, the latter being explained by steroid hormone production. ${ }^{6,7}$ Occasionally patients present with ascites, or with both ascites and pleural effusion (pseudo-Meigs' syndrome). Benign struma ovarii may be associated with ascites in up to $17 \%$ of cases. ${ }^{3,8}$ The ectopic thyroid tissue in struma ovarii may be subject to the same physiological and pathological changes as the thyroid gland. This explains why struma ovarii is sometimes associated with thyrotoxicosis. CA125, the widely accepted tumour marker of ovarian carcinoma, is of little clinical value in struma ovarii patients as it can be elevated in both benign and malignant subtypes. As struma ovarii presents with a variety of non-specific appearances and usually manifests as a multiloculated cystic ovarian mass with solid components of various amounts, the ultrasound typically demonstrates non-specific heterogeneous solid cystic features. ${ }^{9}$

The struma ovarii has features overlapping with those of malignant ovarian epithelial tumours, as it presents either as a unilateral complex adnexal mass often associated with ascites, or as multi-cystic mass with solid components and multiple cystic locules. Thick septations, measuring 3-10 $\mathrm{mm}^{10}$, within the lesion have been described ${ }^{11}$ and the peripheral cyst wall measures $7-15 \mathrm{~mm}$ in thickness ${ }^{11}$ On MR imaging, the signal intensity of the various solid components varies. The classic MR imaging appearance of struma ovarii includes multiple intra-cystic solid areas, representing thyroid tissue, that are of low signal intensity on T2-weighted images and intermediate signal intensity on T1-weighted images. ${ }^{11}$ The cystic spaces, on the other hand, demonstrated both high and low signal intensity on T1- and and T2-weighted images. The high-density spaces seen on CT (especially if $>90 \mathrm{HU}$ ) were of high signal intensity on T1-weighted imaging and low signal intensity on T2-weighted imaging. ${ }^{12}$ Some cystic spaces demonstrated low signal intensity on both T1- and T2-weighted images. This pattern of signal intensity on T1- and T2-weighted imaging was found to be due to the thick, highly viscous, gelatinous colloid material in large follicles of the struma. ${ }^{11-12}$ Joja et al. ${ }^{12}$ stated that the variety of signal intensities seen on MR images in the cystic components depends on the degree of condensation of thyroglobulin and thyroid hormones, and it now recognised that this variable signal intensity is highly characteristic of struma ovarii. Ikeuchi et al. in $2012^{13}$ concluded that a struma typically presents as a lobulated multicystic lesion with solid components, which frequently includes loculi of low signal intensity on T2-weighted, foci of high intensity on T1-weighted images. Imaging following an intravenous contrast agent is known to demonstrate marked enhancement of the thick septations and locally thickened wall seen in struma ovarii. ${ }^{12}$ The solid components, corresponding microscopically to thyroid tissue, also demonstrate strong enhancement ${ }^{12}$ and, together with the multilobulated surface of the struma, gives rise to a "lacy" pattern (This lacy pattern is also apparent on the diffusionweighted images: the hyperintense solid components demonstrating restricted diffusion are interspersed with cystic areas (either hyper- or hypointense on T2-weighted 
imaging) showing increased diffusion. Although MR features of struma ovarii overlap with those of other epithelial ovarian lesions, when MR imaging shows a unilateral complex mass with a multilobulate surface and thickened septa, is composed of multiple cysts of variable signal intensity (in keeping with thick viscous colloid fluid) and demonstrates intensely or moderately enhancing solid components with a "lace appearance", struma ovarii should be included in the differential diagnosis with high probability.

\section{Management}

Struma ovarii is treated by oophorectomy. Pelvic clearance, thyroidectomy and radioactive iodine is recommended for malignant tumours post - treatment follow up is accomplished by serial serum thyroglobulin levels.

\section{CONCLUSION}

The sonographic and MRI features of struma ovary may mimic ovarian malignancy when presented with complex ovarian mass with ascites and elevated CA125 levels. The final diagnosis of struma ovarii is based on pathology examination of resection of cyst /ovary to confirm or exclude malignancy

\section{REFERENCES}

1. Shanbhogue AK, Shanbhogue DKP, Prasad SR, et al. Clinical syndromes associated with ovarian neoplasms: acomprehensive review. Radiographics. 2010;30:903919.

2. SeungChul Yoo, KiHong Chang, MiOk Lyu, SukJoon Chang, HeeSug Ryu, Haeng Soo Kim, Clinical characteristics of struma ovarii, J Gynecol Oncol 2008;2:135-8.

3. Talerman A. Germ cell tumors of the ovary. In Blaustein's Pathology of the Female Genital Tract (3rd edn), Kurman RJ (ed.) Springer Verlag: New York, NY, 2001; 967-1033.

4. Yamashita Y, Hatanaka Y, Takahashi M, Miyazaki K, Oka-mura H. Struma ovarii: MR appearances.Abdom Imaging 1997;22:100 - 102.

5. Ljunberg O. Biopsy Pathology of the Thyroid and Parathyroid. Chapman \& Hall Medical: London, 1992

6. Kempers RD, Dockerty MB, Hoffman DL, Bartholomew LG.Struma ovarii - ascitic, hyperthyroid, and asymptomatic syn-dromes.Ann Intern Med 1970;72: 883 - 893.

7. Costa MA, Povoa AM, Pires MC, Paiva VL, Pinto C, Martinez-de-Oliveira J. Struma ovarii: a rare form of presentation andclinical review.Acta Obstet Gynecol Scand 2005;84: 819 - 820 .

8. Roth LM, Talerman A. The enigma of struma ovarii. Pathology 2007; 39: 139-146

9. Outwater EK, Siegelman ES, Hunt JL. Ovarian teratomas: tumor types and imaging characteristics. Radiographics. 2001;21:475-490.

10. Kim JC, Kim SS, Park JY. MR findings of struma ovarii. J Clin Imaging. 2000;24:28-33.

11. Matsuki M, Kaji Y, Matsuo M, Kobashi Y. Struma ovarii: MRI findings. Br J Radiol. 2000;73:87-90.

12. Ikeuchi T, Koyama T, Tamai K, et al. CT and MR features of struma ovarii. Abdom Imaging. 2012;37:904-910.

\section{Source of Support: Nil; Conflict of Interest: None}

Submitted: 12-02-2020; Accepted: 28-02-2020; Published online: 09-04-2020 